\title{
Determinants of Selective Solidarity Across Borders
}

\author{
Alexandre Afonso and Samir Negash, Leiden University
}

\begin{abstract}
This paper analyses how the characteristics of the recipient country shapes individual support for financial help across borders. Existing literature has shown that individuals are more likely to show solidarity with their co-nationals than for individuals in other countries. However, people might show different levels of solidarity towards different foreign countries depending on their geographical or cultural proximity, their economic conditions or political ties. We make use of a survey experiment asking respondents in 14 European countries whether they think their country should provide financial help to 35 foreign countries in the event of a major crisis to assess different heuristics of international solidarity (need; reciprocity; identity; attitude). We show that shared borders, a common language, geographical proximity and common membership in the European Union are associated with a higher probability of solidarity. We find that ideology has a substantial moderating effect: left-wing and rightwing individuals differ substantially in how they support solidarity with other countries: the solidarity of right-wing individuals across borders is much more conditional (on EU membership, geographical proximity, trade ties) than the solidarity of left-wing individuals.
\end{abstract}

\section{Introduction}

Are people more willing to support financial help for certain countries rather than others? This question arises in the many contexts where international redistribution takes place: foreign development aid, natural disasters, or international fiscal transfers across countries within supranational organizations. Such transfers are especially relevant within the European Union, and have become politicized and controversial amidst economic turmoil in recent years. In the wake of the sovereign debt crisis that affected the Eurozone in 2010-2011, EU countries contributed substantial sums of money to a bailout fund designed to prevent sovereign defaults in Greece, Portugal, Ireland, and Spain, thereby facing substantial domestic opposition in contributing countries (Bechtel et al., 2014; Kleider \& Stoeckel, 2019). In early 2020, EU countries decided to contribute to a rescue fund designed to support the countries most severely hit by the health and economic crisis induced by the Covid-19 pandemic, such as Italy and Spain. Here again, the idea of contributing tax money to help people in other countries proved highly controversial. A 2020 Dutch poll found that $70 \%$ of Dutch voters agreed that EU countries should show solidarity with each other. However, $61 \%$ were against the specific terms of the corona rescue fund which was perceived to benefit Southern European countries (I\&O Research, 2020). If people agree that solidarity beyond borders is important, they may not display the same level of solidarity for any foreign country. Given that international redistribution may play an increasingly important role in future, it is important to examine the drivers of individual preferences for solidarity across borders.

This article analyses whether and how the characteristics of the potential recipient country influence support for solidarity across borders, as well as how individual ideological positions moderate the effect of these characteristics. Drawing on literature on social solidarity within borders, we use different heuristics of solidarity to explore how factors such as the distance between countries, shared borders, a common 
language, differences in wealth and common membership in the European Union relate to the propensity of individuals to support financial help for another country, as well as how these factors interact with individual characteristics. For this purpose, we use a dyadic dataset pairing 18,732 individuals in 14 potential donor countries with 35 potential recipient countries and their characteristics, drawing on a survey conducted by the European University Institute and Yougov in April 2020.

Extant research has shown that individuals tend to discriminate in their solidarity preferences between fellow citizens and people in foreign countries (Kuhn \& Kamm, 2019). Values such as cosmopolitanism have been found to play a more important role than self-interest in attitudes towards international redistribution (Bechtel et al., 2014; Kleider \& Stoeckel, 2019). However, how the characteristics of the country on the receiving end of international redistribution may shape individual preferences has not been explored in spite of its intuitive importance. Meanwhile, a body of literature also demonstrates that within borders, solidarity with a given target group (e.g. the unemployed, disabled) is often conditional on the characteristics and behaviour displayed by these target groups (van Oorschot, 2000). We combine these two literatures to fills this gap using new data and show that right-wing and left-wing individuals vary significantly in the type of countries they are ready to help: the solidarity of right-wing individuals is more selective than that of left-wing individuals.

\section{Heuristics of International Solidarity}

Solidarity can be defined as "the preparedness to share one's own resources with others, be that directly by donating money or time in support of others or indirectly by supporting the state to reallocate and redistribute some of the funds gathered through taxes or contributions » (Stjernø, 2005, p. 2). Two important questions regarding solidarity are how far it should extend and which principle of entitlement should apply - in other words, who deserves to be the recipient of solidarity. In this section, we highlight a number of hypotheses transposing heuristics found to be relevant domestically to international solidarity: identity, need, attitude and reciprocity.

The first important dimension of solidarity relates to its boundaries. For Michael Walzer, what he calls distributive justice "presupposes a bounded world within which distribution takes place: a group of people committed to dividing, exchanging, and sharing social goods, first of all amongst themselves" (Walzer, 1983, p. 31). Because solidarity is bounded, a question is where these boundaries should be placed: around the family, around a city or region, a country, a continent or the whole world? On this subject, much research has shown that solidarity tends to decline beyond the nation-state (Kuhn \& Kamm, 2019), but it is important to ask how far solidarity extends also beyond the nation-state. So far, existing research has implied that solidarity has hard boundaries by using dichotomous measures regarding recipients (e.g national/foreign). However, we argue that solidarity across borders can have soft boundaries and be differentiated depending on the characteristics of the potential recipient country.

For this, we draw on research on social solidarity within the nation state which shows that individuals have different conceptions of deservingness depending on the characteristics of potential recipients (Van 
Oorschot, 2006). Similarly, research on immigration attitudes has shown that beyond generic attitudes towards asylum, the attributes of asylum seekers, such as their religion or employability, also have important effects on the propensity of natives to support their admission or not (Bansak et al., 2016)

The second important dimension of solidarity is its governing principle: based on which principle should solidarity be extended to other individuals? Should it target people who need it the most, those belonging to one's own group, those who might be able to reciprocate in future, or those who show appropriate behaviour? At the domestic level, research has shown that individuals across European countries have fairly consistent preferences regarding who should be assisted through welfare programs or not (Petersen, 2012; Van Oorschot, 2006). One important heuristic used by individuals is the deservingness heuristic, which conveys a normative assessment of whether recipients deserve to be assisted or not (Gilens, 1999). In the next section, we highlight a number of possible ways people apply the deservingness heuristic for assessments of deservingness at the international level: identity, need, attitude, and reciprocity. These pathways are consistent with what previous research indicates are important criteria to adjudicate deservingness in domestic settings (van Oorschot 2000; 2006). In this section, we first outline a number of hypotheses related to the characteristics of the potential recipient country, and then to how individual characteristics may moderate the relationship between the characteristics of the recipient country and the support for financial assistance.

\section{Identity}

Identity, understood as the proximity between individuals and the target or their solidarity, has been understood to be an important structuring principle of solidarity. In early social psychology experiments conducted in the 1970s, individuals were more likely to allocate resources to members of their own ingroup, and preferred maximizing the difference between their own group and others even if this meant lower gains (Tajfel, 1974). A number of authors have shown that people tend to favour solidarity with people with whom they share a feeling of common identity or shared origin, for instance along national, cultural or racial lines. This mechanism has been especially prominent in the United States, where authors such as Martin Gilens have shown that redistribution has been severely hampered by ethnic and racial divisions: people tend to prefer to redistribute within their group rather than across groups (Gilens, 1999; Shayo, 2009). For instance, Luttmer (2001) found that if support for redistribution was negatively correlated with local dependency rates as a whole, it was positively correlated with dependency rates within one's own racial group: people are less likely to support redistribution if there are more welfare recipients, but more likely to support it if there are more welfare recipienst that look like them. Similarly, Europeans tend to favour redistribution for their own fellow citizens rather than for foreigners (Kuhn \& Kamm, 2019). If race and nationality have played a very prominent role in structuring solidarity, what the relevant group is to allocate resources and what its boundaries are can be shaped by context and history.

Transposing this idea to international solidarity, we could expect citizens to be more favourable to solidarity with countries with whom they share a feeling of kinship or proximity, as translated by shared 
borders, geographical proximity or a common language. Because a German citizen might feel closer culturally to Austria than to Japan, they may be more willing to help the former than the latter in time of need. Identity in this context can be operationalized with indicators such as geographical proximity, shared borders or a common language.

Hypothesis 1: Individuals are more likely to support help for countries that are culturally and geographically closer or similar

\section{Need}

The second potential criterion of international solidarity we examine is need. This can be understood as the most purely altruistic heuristic insofar as the willingness to help is determined by the level of need of the recipient country, as measured for instance by economic indicators such as GDP per capita. Here, motivations would be guided by altruism defined as "the willingness to incur a loss of material welfare to enhance the welfare (material or otherwise) of others" (Elster, 2006, p. 186). In this case, the willingness to help another country would be guided by the economic circumstances of the potential recipient country. Hence, we could expect individuals to be more willing to help poorer countries than the one where they live, and less willing to help countries that are richer than their own. People might think for instance that rich countries such as Luxembourg or Denmark can fend for themselves in the event of a major crisis, while poorer countries such as Tunisia or Vietnam can't overcome a crisis without external help.

Here again, the rationale for these expectations can be found in findings from social psychology where individuals were found to manifest other-regarding preferences that depart from pure self-interest, and an aversion to inequality in general (Charness \& Rabin, 2002; Dimick et al., 2018). The propensity to want to help poor countries might not only be guided by altruistic concerns - for instance, people may want to assist poorer countries in the event of a disaster to prevent migration flows to the north - but this yardstick is still clearly different from the idea of identity or reciprocity that we outline in the next section.

Hypothesis 2a: The willingness to support financial help is higher when target countries are poorer.

Hypothesis $2 \mathrm{~b}$ : The willingness to support financial help is greater when the target country is poorer than one's own country and when the target country's GDP is s.

\section{Reciprocity}

The third potential driver of international solidarity is reciprocity (Konow, 2003). In general, individuals may consider helping others if their contribution or effort is expected to be matched by contributions and efforts by other actors in the future, that is, if other pay their way (Falk et al., 2008). Here, we refer more to what Molm et al. (2007, pp. 207-208) call direct reciprocity, namely a system where exchange takes places between two actors and is characterized by "a "quid pro quo" mentality and strict accounting, intensely 
self-interested actors who engage in frequent conflict over the fairness of exchange, and low levels of trust and solidarity".

At the basic level, individuals may be more willing to help countries in better economic circumstances in times of need insofar as they would also be better able to reciprocate if needed. To give one example, if individuals in Norway decide to help Nigeria or India, the likelihood that these countries will be in a position to reciprocate is fairly small given their comparative economic wealth and tenuous institutional ties compared to neighboring countries. On the other hand, helping Denmark may cement trust with countries that will reciprocate and are in a position to do so, notably through an institutional system of mutual commitments. In this context, the driver of solidarity is less motivated by pure altruism but more by self-interest. For instance, one may expect that individuals may be more willing to help countries with which their country has intense economic relationships, for instance through international trade, rather than those with which they do not. Here, solidarity is more driven by self-interest.

Another mechanism that can facilitate reciprocity is membership in international organizations that ensure some level of mutual commitment and fiscal assistance between countries. This is probably nowhere as institutionalized as in the European Union. Even if fiscal redistribution across countries as such has faced important barriers (Scharpf, 2010), there are now a number of mechanisms that sustain redistribution between EU countries, such as the European Stability Mechanism (ESM). In this context, people may be more willing to help fellow EU members than non-Members because the former have some institutional duty of assistance via the EU institutional framework, whereas the latter do not. Of course, the greater willingness to help other EU countries may be guided by other considerations than self-interest; for instance, individuals may feel a sense of responsibility towards other EU countries without necessarily expecting reciprocity. Hence, being more willing to help other EU countries might as well be driven by the identity heuristic. When we look at interactions with individual ideology, we will be able to have some leverage on underlying ideological factors. It is important to highlight the multiple function of the European Union: it can be understood as a system of commitment facilitating reciprocity, but also as a vector of identity. In this paper we use it as the former, even if we keep other possibilities open.

Hypothesis 3a: Individuals are more likely to support financial help for richer countries

Hypothesis $3 b$ : Individuals are more likely to support financial help for countries that have higher volumes of trade with their home country

Hypothesis 3c: Individuals are more likely to support financial help for countries that are also members of the European Union

\section{Attitude}

A final heuristic individuals may use to form judgments about whether potential recipient countries deserve financial help is what Meuleman et al. (2020) call attitude. If they understand this idea at the individual level as the demonstration of gratitude and compliance, we could also understand this as the inclusion of 
some criterion of good behaviour. Historically, social assistance has often been conditioned on some criterion of moral behaviour, from the old paternalism and workhouses of the $19^{\text {th }}$ century to the workfare policies of the $21^{\text {st }}$, for requiring active job search in order to deserve unemployment benefits. In order to deserve assistance, individuals need to show compliance with some moral standard. Transposed to the international context, we could expect individuals to be more favorable to helping countries with a higher moral standing or better transparency when it comes to the use of said financial help, for instance as measured by perceptions of corruption, the level of democracy or fiscal prudence. Perceived levels of corruption may also be a factor that influences how individuals anticipate how the financial help will be used: they may prefer to help a poor country that is not corrupt and where the help will be used more effectively to relieve a crisis. We also use government debt as a percentage of GDP as a factor of attitude possibly perceived by individuals as a factor of fiscal prudence, even if we're aware that government debt can be the results of complex economic circumstances beyond the control of governments.

Hypothesis 4. Individuals are more likely to support help for countries showing better indicators of good behaviour in transparency and fiscal prudence.

\section{Individual ideology as moderating variable}

Individuals of different ideological persuasions may rely on different heuristics in their attitudes towards solidarity across borders. In general, political beliefs may be important factors shaping moral judgments that underpin solidarity (Hatemi et al., 2019). Hence, individual ideological positions can act as a moderating factor in the relationship between the characteristics of the recipient country and the propensity to support financial help. Yet, in their analysis of attitudes towards solidarity across borders, Kuhn and Kamm (2019, p. 192) find that economic left-right positions do not have an impact on attitudes towards international redistribution. In line with this finding, Bechtel et al. (2014) also find that economic left-right positions do not have an impact on attitudes towards international redistribution, but what they call "cosmopolitanism" does. Earlier research does, however, show that the more right-wing a person is, the more conditional solidarity becomes on meeting the deservingness criteria (van Oorschot 2000). So, even if individuals of different ideological persuasions do not differ with regards to their overall support for international solidarity, the interaction between the features of the target and individual ideology may produce differences in support for international solidarity.

However, if ideology indicates greater conditioning of solidarity on the deservingness of the candidate, previous research has not explained which criteria should matter to individuals with different ideologies. Giger and Nelson (2012) show that whereas left-wing individuals are unconditional supporters of the welfare state and oppose cuts to it regardless of the economic costs, right-wing individuals are more sensitive to the economic and fiscal consequences of the welfare state. We believe that similar dynamics are at play when it comes to international redistribution. We believe that all things being equal, right-wing individual may favour help for different types of countries than left-wing individuals. Insofar as the 
heuristic of need involves a greater element of redistribution without necessarily a counterpart, this heuristic can reasonably be expected to be more prevalent among left-wing individuals who are more averse to inequality across countries. In contrast, more right-wing individuals may be less prone to support help for poorer countries. We also expect solidarity for right-wing individuals to be more conditional on the possibility of reciprocity in the future. Therefore, we expect the wealth of the target country to increase the likelihood that right-wing individuals support aid to a country. Similarly, we expect that right-wing individuals are more likely to endorse financial support to countries in the EU and for them to support aid to countries that are of economic importance to the source country (reciprocity). In addition, we expect more right-wing individuals to support help for countries that are perceived to be closer culturally and geographically (identity). In the US, Waytz et al (2019) show that right-wing individuals have a narrower, more parochial conception of solidarity while left-wing individuals have a more universalistic conception of solidarity. In contrast to right-wing individuals, left-wing individuals' sense of solidarity does not depend on social proximity. Applied to our study, we could expect ideology to affect the effects of geographic, linguistic and social proximity on likelihood of supporting international support for other countries.

Hypotheses 5a: The more right-wing individuals are, the more likely they are to support help for countries that are linguistically or geographically closer

Hypothesis 5b: The more right-wing an individual is, the more likely they are to support countries who can reciprocate aid

Hypothesis 5c: The more left-wing an individual is, the more likely they are to support help for countries that display greater need

Hypothesis 5d: The more right-wing an individual is, the less likely they are to support countries who have not displayed good behaviour

\section{Data and Methods}

To test our hypotheses, we use the EUI-YouGov survey on solidarity in Europe (Genschel et al., 2020). This is a survey now available in open access conducted between the $17^{\text {th }}$ and $29^{\text {th }}$ April 2020 by Yougov and the Robert Schuman Centre of the European University Institute on a representative sample of more than 20'000 adults in 14 European countries (Finland, France, Germany, Greece, Hungary, Italy, Lithuania, Netherlands, Poland, Romania, Spain, Sweden, United Kingdom). The survey covered a range of topics linked to solidarity in Europe, including the concept of solidarity among EU states and beyond; response to different crises; satisfaction and trust towards governments, the EU and international actors; strength of national and European identities; value of democracy; importance and salience of various issues and threats; intention in a EU-membership referendum and other EU-related indicators including differentiated 
integration; world politics; left-right self-placement; gender, religion and age group and vote record in past national elections.

Dependent variable. For this paper we use one question asked in this survey as dependent variable: "Imagine a country suffered some kind of major crisis, and was looking for help from others. Do you think [country of respondent] should or should not be willing to offer financial help to each of the following countries?". Respondents were randomly presented with 9 out of 35 possible countries except their own ${ }^{1}$ and asked whether their home country should be willing to help the country in question. We reshaped the dataset as a dyadic dataset to obtain respondent-recipient country pairs as rows/units of analysis. The dataset contains responses from 18'732 respondents and totals 151,478 observations (respondent/targetcountry pairs). The variable is coded as 1 if the respondent supports help for the country in question, and 0 if he or she doesn't. We have recoded don't knows as missing for the purpose of the analysis.

Independent variables. We use independent variables at two levels: the dyadic relationship between the country of the respondent and the recipient country, and individual characteristics of respondents. For each sender-recipient country pair, we computed a number of indicators designed to capture the relationship between the sender and recipient country. Country pairs. For the identity dimension, we first calculated the distance between the centre of the two countries using the geodist package in Stata (Picard, 2019). We also use variables coding whether countries share a border or not (GeoDataSource, n.d.), or have a common official language (Melitz \& Toubal, 2014). As a specific dimension of identity, we also used the scaled social connected index (Bailey et al., 2018), which - based on data from the social media platform Facebook - provides a probability that two individuals in a given country pair are friends on that platform. This can capture social connections between different countries, but because its is scaled on the total population of the country pair, in some cases is also driven by important diasporas. For the need dimension, we use the log of GDP per capita in current USD in 2019 in the donor and recipient country, and calculated a ratio of the GDP per capita in the target and source country to obtain an indicator of the difference in wealth with data from the World Bank (World Bank, 2020). For reciprocity, we coded whether country pairs were both members of the European Union or not, added GDP per capita 2019 from the world bank, and constructed an indicator of the volume of bilateral trade between each country pair, namely the sum of exports and imports in 2019 as a share of 2019 GDP in USD, coming from the Atlas of Economic Complexity at Harvard (The Growth Lab At Harvard University, 2019). For the attitude dimension, we use the corruption perception index of transparency international (Transparency international, 2020), the VDem indicator of democracy and government debt as a \% of GDP from the International Monetary Fund. Individual variables. For individual variables, we use individual left-right positioning on a scale from 1 (very left-wing) to 7 (very right-wing). We control for a number of possible confounders at the individual level, including, age, gender and subjective economic security, measured by a self-assessment of how welloff an individual is compared to their age group. Unfortunately, there is not indicator of education in the survey.

\footnotetext{
${ }^{1}$ The option were Austria, Belgium, Bulgaria, Canada, Colombia, Croatia, Cyprus, Czech Republic, Denmark, Estonia, Finland, France, Germany, Greece, Hungary, India, Ireland, Italy, Japan, Latvia, Lithuania, Luxembourg, Malta, Netherlands, Nigeria, Poland, Portugal, Romania, Slovakia, Slovenia, Spain, Sweden, Tunisia, Vietnam, United Kingdom.
} 
Our data has a nested structure, with respondent-target country variables nested in individuals, who are themselves nested in source countries. As each individual makes several assessments, each of which is counted as a separate observation, this makes our design similar to within-subject designs often employed in factorial survey designs where each respondent is exposed to multiple treatments (Kim, 2012). As these observations are not independent of each other, either at the respondent-target country level or on the individual-level, we employ a three-level multilevel model. Because the response variable is binary and the range of the outcome variable is restricted, estimating a linear model would be inappropriate as the fitted values may fall outside this range. Moreover, the use of a linear model could also produce heteroscedastic errors with a binary outcome variable. We therefore estimate multilevel logistic regression models (Snijders \& Bosker, 2012).

\section{Results}

To give an overview of the data, Table 1 shows a matrix of each source and target country with the share of respondents in each source country supporting help for each target country. This results in a matrix of 476 combinations. The colour code indicates the level of support, with red values showing higher values and blue ones lower values. The dataset contains $151^{\prime} 478$ observations, meaning that each cell in the matrix draws on an average of 318 individuals that have given a yes or no answer. It is important to say that we have removed "Don't knows", which represented $22.72 \%$ of all observations. The matrix gives an overview of some tendencies in the data: for instance, $88 \%$ of Spanish respondents who expressed an opinion support financial help for Portugal, and $85 \%$ of Dutch respondents support help for Belgium. Finland is the European country with the lowest share of respondents supporting help for other countries, while Spain is the one with the highest share. We can clearly see that non-EU countries tend to have much lower levels of support. This is especially the case for the United Kingdom, which enjoys similar levels of support as Tunisia and Colombia, and lower than Nigeria or Vietnam. This is probably the result of a "Brexit sanction" by respondents in other member states. 
Table 1: Proportion of respondents in each source country (rows) expressing support for financial help in each target country (columns)

\begin{tabular}{|c|c|c|c|c|c|c|c|c|c|c|c|c|c|c|c|c|c|c|c|c|c|c|c|c|c|c|c|c|c|c|c|c|c|c|c|c|}
\hline & 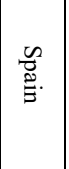 & $\stackrel{\overrightarrow{\vec{E}}}{\vec{v}}$ & 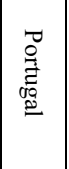 & 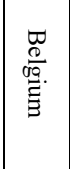 & $\begin{array}{l}\overrightarrow{\vec{\sigma}} \\
\frac{\overrightarrow{\tilde{\nu}}}{2}\end{array}$ & $\begin{array}{l}\text { 胥 } \\
\text { 壳. }\end{array}$ & 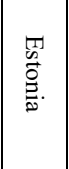 & 苃. & 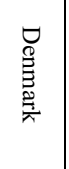 & 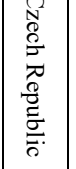 & $\begin{array}{l}\text { Tu } \\
\text { E्: } \\
\text { 产 }\end{array}$ & $\begin{array}{l}\tilde{D} \\
\tilde{0} \\
\stackrel{0}{*}\end{array}$ & 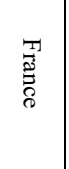 & 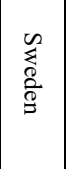 & $\begin{array}{l}\frac{\infty}{0} \\
\stackrel{0}{\alpha} \\
\stackrel{0}{2} .\end{array}$ & $\begin{array}{l}\text { Q } \\
\mathbb{8} \\
\stackrel{0}{0} \\
\delta\end{array}$ & 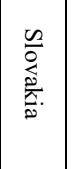 & 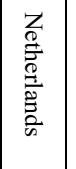 & $\begin{array}{l}\text { : } \\
\text {. } \\
\text { 产. }\end{array}$ & $\begin{array}{l}\frac{\overrightarrow{0}}{2} \\
\frac{\hat{2}}{2}\end{array}$ & 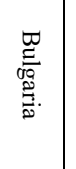 & 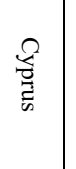 & 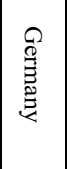 & $\frac{3}{\sqrt[2]{*}}$ & 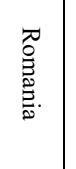 & 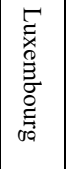 & 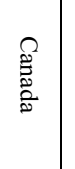 & 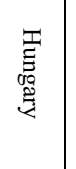 & 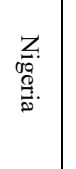 & 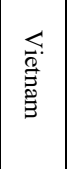 & $\vec{E}$ & $\begin{array}{l}\stackrel{\widetilde{\sharp}}{\dddot{\Xi}} \\
\end{array}$ & $\overrightarrow{\vec{E}}$. & $\stackrel{\Xi}{\lambda}$ & $\begin{array}{l}\frac{\delta}{0} \\
\frac{0}{0} \\
\frac{0}{2}\end{array}$ & 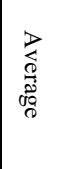 \\
\hline Spain & & 0.81 & 0.88 & 0.63 & 0.73 & 0.66 & 0.70 & 0.68 & 0.67 & 0.72 & 0.61 & 0.70 & 0.74 & 0.64 & 0.71 & 0.82 & 0.71 & 0.56 & 0.72 & 0.71 & 0.72 & 0.71 & 0.61 & 0.71 & 0.71 & 0.64 & 0.56 & 0.70 & 0.71 & 0.61 & 0.67 & 0.58 & 0.63 & 0.42 & 0.63 & 0.70 \\
\hline Poland & 0.76 & 0.75 & 0.69 & 0.73 & 0.71 & 0.66 & 0.75 & 0.72 & 0.62 & 0.79 & 0.66 & 0.77 & 0.62 & 0.61 & 0.71 & 0.63 & 0.76 & 0.60 & 0.77 & & 0.73 & 0.63 & 0.60 & 0.66 & 0.75 & 0.54 & 0.65 & 0.68 & 0.70 & 0.580 & 0.65 & 0.58 & 0.58 & 0.57 & 0.49 & 0.69 \\
\hline Romania & 0.77 & 0.76 & 0.70 & 0.72 & 0.66 & 0.64 & 0.71 & 0.66 & 0.59 & 0.76 & 0.68 & 0.68 & 0.62 & 0.58 & 0.77 & 0.73 & 0.73 & 0.63 & 0.74 & 0.73 & 0.81 & 0.68 & 0.62 & 0.63 & & 0.62 & 0.54 & 0.61 & 0.60 & 0.630 & 0.61 & 0.53 & 0.58 & 0.55 & 0.62 & 0.69 \\
\hline Denmark & 0.75 & 0.73 & 0.71 & 0.80 & 0.74 & 0.81 & 0.70 & 0.71 & & 0.65 & 0.79 & 0.65 & 0.71 & 0.79 & 0.62 & 0.66 & 0.65 & 0.79 & 0.63 & 0.62 & 0.62 & 0.64 & 0.77 & 0.67 & 0.60 & 0.71 & 0.64 & 0.57 & 0.49 & $0.50 \quad 0$ & 0.51 & 0.46 & 0.46 & 0.60 & 0.44 & 0.71 \\
\hline Germany & 0.77 & 0.75 & 0.75 & 0.76 & 0.70 & 0.82 & 0.67 & 0.67 & 0.78 & 0.69 & 0.73 & 0.67 & 0.76 & 0.74 & 0.62 & 0.63 & 0.64 & 0.80 & 0.62 & 0.57 & 0.61 & 0.63 & & 0.66 & 0.56 & 0.70 & 0.62 & 0.52 & 0.51 & $0.50 \quad 0$ & 0.51 & 0.52 & 0.46 & 0.42 & 0.39 & 0.70 \\
\hline Italy & 0.78 & & 0.72 & 0.65 & 0.63 & 0.55 & 0.64 & 0.68 & 0.56 & 0.68 & 0.59 & 0.76 & 0.55 & 0.51 & 0.71 & 0.82 & 0.65 & 0.50 & 0.67 & 0.68 & 0.64 & 0.65 & 0.43 & 0.59 & 0.64 & 0.53 & 0.56 & 0.54 & 0.62 & 0.610 & 0.60 & 0.59 & 0.57 & 0.47 & 0.56 & 0.64 \\
\hline UK & 0.64 & 0.62 & 0.63 & 0.63 & 0.77 & 0.59 & 0.56 & 0.58 & 0.67 & 0.59 & 0.66 & 0.59 & 0.58 & 0.61 & 0.60 & 0.64 & 0.62 & 0.68 & 0.54 & 0.66 & 0.56 & 0.69 & 0.60 & 0.72 & 0.58 & 0.57 & 0.74 & 0.58 & 0.54 & 0.530 & 0.60 & 0.47 & 0.55 & & 0.48 & 0.62 \\
\hline Lithuania & 0.65 & 0.64 & 0.62 & 0.59 & 0.67 & 0.64 & 0.80 & 0.83 & 0.64 & 0.71 & 0.68 & 0.63 & 0.65 & 0.63 & 0.67 & 0.50 & 0.62 & 0.60 & & 0.74 & 0.72 & 0.53 & 0.67 & 0.54 & 0.56 & 0.60 & 0.53 & 0.65 & 0.41 & 0.430 & 0.39 & 0.46 & 0.31 & 0.48 & 0.32 & 0.66 \\
\hline Sweden & 0.64 & 0.63 & 0.58 & 0.64 & 0.62 & 0.66 & 0.67 & 0.63 & 0.76 & 0.56 & 0.80 & 0.59 & 0.62 & & 0.54 & 0.56 & 0.54 & 0.62 & 0.60 & 0.50 & 0.50 & 0.54 & 0.62 & 0.55 & 0.47 & 0.50 & 0.48 & 0.42 & 0.54 & 0.490 & 0.44 & 0.45 & 0.36 & 0.53 & 0.40 & 0.61 \\
\hline Netherlands & 0.63 & 0.56 & 0.63 & 0.85 & 0.71 & 0.78 & 0.58 & 0.57 & 0.74 & 0.56 & 0.69 & 0.57 & 0.62 & 0.71 & 0.49 & 0.47 & 0.48 & & 0.52 & 0.53 & 0.40 & 0.47 & 0.83 & 0.51 & 0.47 & 0.77 & 0.65 & 0.44 & 0.42 & 0.390 & 0.39 & 0.39 & 0.35 & 0.47 & 0.29 & 0.61 \\
\hline Greece & 0.75 & 0.80 & 0.73 & 0.39 & 0.60 & 0.50 & 0.58 & 0.55 & 0.44 & 0.56 & 0.37 & 0.55 & 0.68 & 0.52 & 0.58 & & 0.58 & 0.55 & 0.56 & 0.56 & 0.62 & 0.86 & 0.30 & 0.63 & 0.62 & 0.41 & 0.49 & 0.47 & 0.62 & $0.50 \quad 0$ & 0.45 & 0.39 & 0.52 & 0.30 & 0.43 & 0.57 \\
\hline France & 0.69 & 0.69 & 0.63 & 0.68 & 0.54 & 0.52 & 0.44 & 0.50 & 0.54 & 0.51 & 0.54 & 0.47 & & 0.55 & 0.45 & 0.55 & 0.47 & 0.54 & 0.45 & 0.49 & 0.50 & 0.45 & 0.60 & 0.49 & 0.46 & 0.48 & 0.49 & 0.45 & 0.45 & $0.40 \quad 0$ & 0.41 & 0.29 & 0.36 & 0.33 & 0.30 & 0.54 \\
\hline Hungary & 0.53 & 0.58 & 0.45 & 0.52 & 0.43 & 0.62 & 0.45 & 0.50 & 0.50 & 0.58 & 0.40 & 0.66 & 0.46 & 0.45 & 0.62 & 0.55 & 0.59 & 0.46 & 0.46 & 0.64 & 0.58 & 0.38 & 0.46 & 0.47 & 0.50 & 0.39 & 0.33 & & 0.44 & 0.360 & 0.40 & 0.39 & 0.36 & 0.40 & 0.28 & 0.52 \\
\hline Finland & 0.48 & 0.44 & 0.52 & 0.60 & 0.54 & 0.57 & 0.75 & 0.60 & 0.70 & 0.48 & & 0.51 & 0.48 & 0.70 & 0.48 & 0.40 & 0.48 & 0.54 & 0.58 & 0.39 & 0.40 & 0.40 & 0.55 & 0.35 & 0.46 & 0.45 & 0.35 & 0.32 & 0.26 & 0.350 & 0.23 & 0.29 & 0.25 & 0.27 & 0.21 & 0.53 \\
\hline Average & 0.68 & 0.67 & 0.66 & 0.66 & 0.65 & 0.64 & 0.64 & 0.63 & 0.63 & 0.63 & 0.63 & 0.63 & 0.62 & 0.62 & 0.61 & 0.61 & 0.61 & 0.60 & 0.60 & 0.60 & 0.60 & 0.59 & 0.59 & 0.59 & 0.57 & 0.56 & 0.55 & 0.53 & 0.52 & 0.490 & 0.49 & 0.46 & 0.45 & 0.45 & 0.42 & \\
\hline
\end{tabular}


Turning to our results, based on the intra-class correlation coefficient, we found that in the null model in column 1 of table 2 that the vast majority of the variance is at the first two levels, collectively accounting for approximately $98 \%$ of the variance - about 77 percent of which could be attributed to the respondenttarget country level. We first went on to estimate the relationships between our predictors and our outcome variables sequentially gauging the effects of each deservingness heuristic. The results of the regression models are presented in Table 2.

In Model 2, we can see that - consistent with our expectations - identity-related factors contribute statistically significantly to shaping support for help for other countries. Specifically, we can see that the likelihood that individuals support financial help for a country decreases with distance, while sharing a border increases the likelihood of supporting help by 0.66 log-odds. In line with our expectations, having a common language also increases the likelihood that people support helping another country. More extensive social contacts as measured by the SCI indicator also has a statistically significant positive effect on supporting financial relief for other countries.

Model 3 in column 3 analyses the effect of need-based factors. In the model containing only the need-based predictors and our controls, we find different effects for the absolute level of wealth of the target country measured by the target country's GDP per capita logged and the relative level of wealth compared to the country of the respondent. The indicator for the relative level of wealth is a ratio of the GDP per capita of the target country divided by the GDP per capita of the country of the respondent, so that values below one mean that the target country is poorer, and values above 1 that it is richer. It is interesting to see that the effect of the absolute level of wealth loses significance in the full model, while the relative level of wealth stays significant and has the expected sign considering the need heuristic: controlling for other factors, people are less likely to support help for countries that are richer than the one where they live.

Model 4 contains the model gauging the effects of reciprocity. Here, both common EU membership and the trade share as a percent of GDP have a significant positive effect. However, the effect of the trade volume loses significance in the full model while common EU membership stays significant with a fairly strong effect size: controlling for other factors, EU membership increases the probability of support for financial assistance by 0.6 log-odds. This would indicate that respondents are more likely to support help for other EU member states than for non-EU members by some margin, but whether there is a lot of trade does not seem to matter. Because common EU membership could also be envisaged as an identity-related variable, empirical support for reciprocity-based heuristics as an overarching driver of solidarity is uncertain.

Model 5 shows that individuals are more likely to support help for countries that are more democratic and less corrupt. Public debt has the opposite sign than we expected following the attitude heuristic: namely, higher government debt is associated with a higher probability of solidarity. One interpretation of this would be that individuals consider countries with a lower public debt to be in a better in a position to fend for themselves; regardless, the results do not suggest that individuals consider debt as an indicator of bad attitude.

Turning to Model 6, we present here the full model with all our predictors. We can see that most of the 
effects discussed in the earlier models are similar in this model, albeit often more modest in the strength of the effects. As mentioned above, the effect of GDP per capita of the target country loses significance; so does the effect of the bilateral volume of trade. All other effects remain statistically significant. As for our control variables, older individuals are consistently statistically significantly less likely to support financial help for countries in crisis. Women or men are no more likely to express support for other countries. The more financially insecure an individual feels, the less likely they are to support financial help for other countries. At the country level, a higher number of cumulative covid deaths is also associated with a higher probability of support for fiscal assistance, which was to be expected given the period under which fieldwork was undertaken for the survey. 
Table 2: Multilevel logistic regression of deservingness criteria and support for help

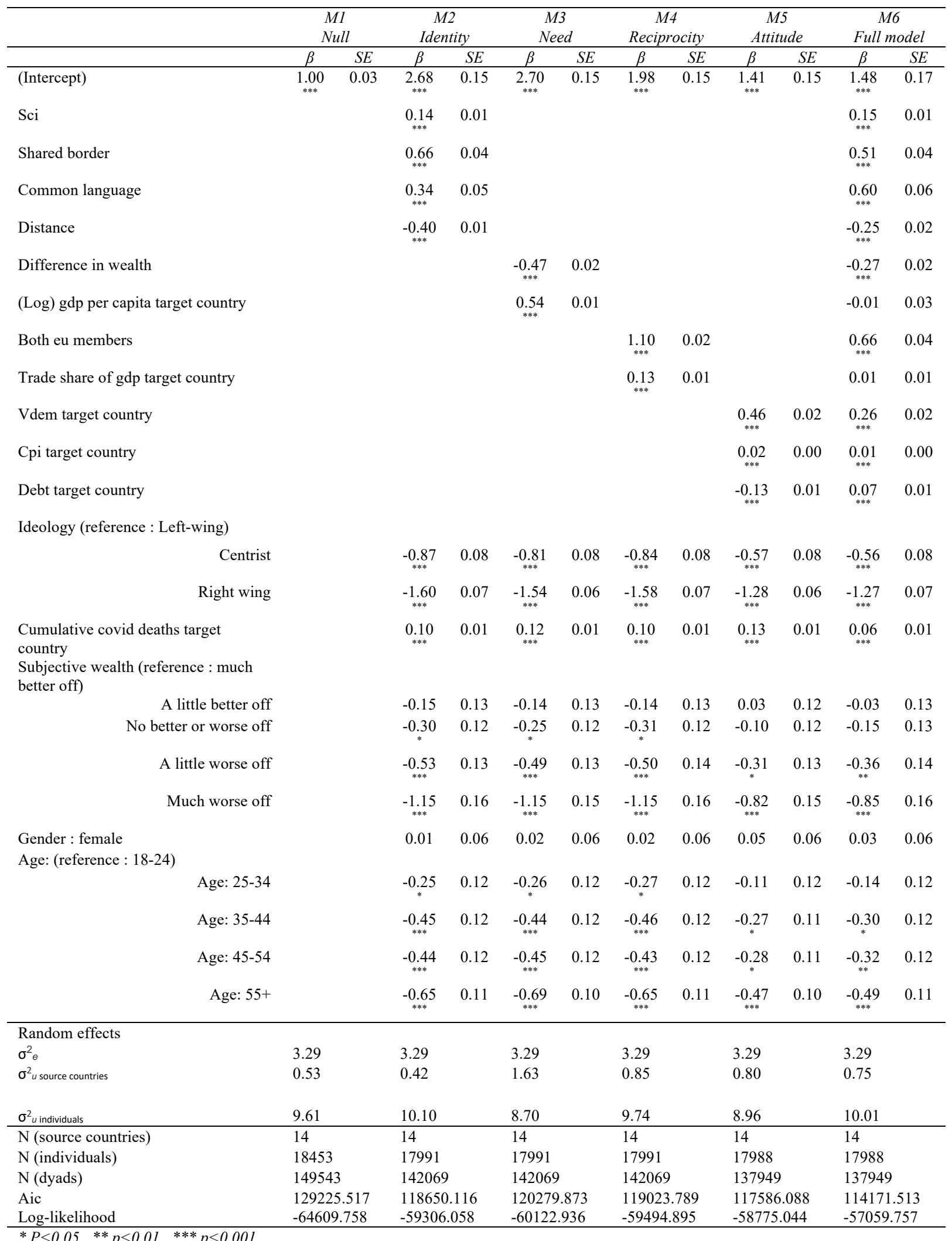


As for the moderating effect of ideology, we examine this further in a set of models in Table 3. First, we look at how identity-based factors (distance, common language and shared borders) are moderated by ideology in solidarity assessments in model 7. We see that centrist and right-wing individuals are not statistically significantly different from left-wing individuals in their likelihood to support help for countries sharing a border or having a common language. They are, however, significantly less likely than left-wing individuals to support help for countries that are more distant geographically. This is consistent with the idea that right-wing individuals are more likely to use the identity heuristic when making solidarity assessments as outlined in hypothesis $5 \mathrm{a}$.

In model 8 , we have interesting findings on the interaction between individual ideology and reciprocitybased factors, namely common EU membership and the volume of trade. Somewhat surprisingly, being a member of the EU has a stronger effect on support for right-wing and centrist individuals than for left-wing respondents. This could be surprising when taking into account that left-wing individuals tend to be more supportive of the EU. But here it seems that left-wing individuals discriminate less between EU and nonEU members in their support for international solidarity compared to individuals that are more on the right, whose solidarity is Imore conditional on common membership in the EU. Thus, even if left-leaning individuals have a greater attachment to the EU, they are no more likely to support allocating their country's funds in ways that favour other EU member states over non-EU countries. The main effect of trade volume is positive, but was statistically insignificant and the conditional effects has a positive sign and is statistically significant only for right-wing individuals. Hence, the volume of trade has a stronger positive effect only for individuals on the right end of the political spectrum. This is consistent with our expectation in hypothesis $5 \mathrm{~b}$, that right-leaning individuals are more likely to value the potential of reciprocity. 
Table 3: Conditional effects of ideology

\begin{tabular}{|c|c|c|c|c|c|c|c|c|}
\hline & Identity & & Reciprocity & & Need & & Attitude & \\
\hline & Model 7 & & Model 8 & & Model 9 & & Model 10 & \\
\hline & B & SE & $\beta$ & SE & $\beta$ & SE & $\beta$ & SE \\
\hline (Intercept) & $1.45 * * *$ & 0.17 & $1.58 * * *$ & 0.17 & $1.52 * * *$ & 0.17 & $1.10 * * *$ & 0.19 \\
\hline Ideology (reference : Left-wing) & Reference & & Reference & & Reference & & Reference & \\
\hline Centrist & $-0.60 * * *$ & 0.08 & $-0.65 * * *$ & 0.10 & $-0.59 * * *$ & 0.08 & -0.15 & 0.18 \\
\hline Right wing & $-1.26 * * *$ & 0.07 & $-1.42 * * *$ & 0.08 & $-1.28 * * *$ & 0.07 & $-0.63 * * *$ & 0.14 \\
\hline Sci & $0.15 * * *$ & 0.02 & $0.16 * * *$ & 0.01 & $0.16 * * *$ & 0.01 & $0.16 * * *$ & 0.01 \\
\hline Sci $x$ centrist & -0.02 & 0.03 & & & & & & \\
\hline Sci $x$ right-wing & 0.00 & 0.03 & & & & & & \\
\hline Shared border & $0.49 * * *$ & 0.07 & & & & & & \\
\hline Shared border $x$ centrist & 0.05 & 0.11 & & & & & & \\
\hline Shared border $\mathrm{x}$ right-wing & 0.02 & 0.09 & & & & & & \\
\hline Common language & $0.48 * * *$ & 0.10 & $0.81 * * *$ & 0.05 & $0.81 * * *$ & 0.05 & $0.81 * * *$ & 0.05 \\
\hline Common language $x$ centrist & 0.09 & 0.16 & & & & & & \\
\hline Common language $x$ right-wing & 0.22 & 0.13 & & & & & & \\
\hline Distance & $-0.13 * * *$ & 0.02 & $-0.29 * * *$ & 0.02 & $-0.28 * * *$ & 0.02 & $-0.28 * * *$ & 0.02 \\
\hline Distance $x$ centrist & $-0.13 * * *$ & 0.03 & & & & & & \\
\hline Distance $x$ right-wing & $-0.21 * * *$ & 0.02 & & & & & & \\
\hline Difference in wealth & $-0.27 * * *$ & 0.02 & $-0.28 * * *$ & 0.02 & $-0.24 * * *$ & 0.03 & $-0.28 * * *$ & 0.02 \\
\hline Difference in wealth $x$ centrist & & & & & 0.06 & 0.05 & & \\
\hline Difference in wealth $x$ right-wing & & & & & $-0.11 * *$ & 0.04 & & \\
\hline (Log) gdp per capita target country & -0.01 & 0.03 & 0.01 & 0.03 & $-0.21 * * *$ & 0.04 & -0.00 & 0.03 \\
\hline ( Log) gdp per capita target country $x$ centrist & & & & & $0.11 *$ & 0.04 & & \\
\hline (Log) gdp per capita target country $x$ right-wing & & & & & $0.37 * * *$ & 0.03 & & \\
\hline Both EU members & $0.64 * * *$ & 0.04 & $0.48 * * *$ & 0.05 & $0.65 * * *$ & 0.04 & $0.65 * * *$ & 0.04 \\
\hline Both $\mathrm{EU}$ members $\mathrm{x}$ centrist & & & $0.14 *$ & 0.07 & & & & \\
\hline Both EU members $x$ right-wing & & & $0.24 * * *$ & 0.06 & & & & \\
\hline Trade share of gdp target country & 0.01 & 0.01 & 0.02 & 0.02 & $0.05 * * *$ & 0.01 & $0.05 * * *$ & 0.01 \\
\hline Trade share of gdp target country $x$ centrist & & & 0.04 & 0.03 & & & & \\
\hline Trade share of gdp target country $x$ right-wing & & & $0.06 * *$ & 0.02 & & & & \\
\hline Vdem target country & $0.27 * * *$ & 0.02 & $0.26 * * *$ & 0.02 & $0.26 * * *$ & 0.02 & $0.32 * * *$ & 0.04 \\
\hline Vdem target country $x$ centrist & & & & & & & -0.10 & 0.07 \\
\hline Vdem target country $x$ right-wing & & & & & & & -0.07 & 0.05 \\
\hline Cpi target country & $0.01 * * *$ & 0.00 & $0.01 * * *$ & 0.00 & $0.01 * *$ & 0.00 & $0.02 * * *$ & 0.00 \\
\hline Cpi target country $x$ centrist & & & & & & & $-0.02 * * *$ & 0.00 \\
\hline Cpi target country $x$ right-wing & & & & & & & $-0.02 * * *$ & 0.00 \\
\hline Debt target country & $0.07 * * *$ & 0.01 & $0.08 * * *$ & 0.01 & $0.08 * * *$ & 0.01 & $0.11 * * *$ & 0.02 \\
\hline Debt target country $x$ centrist & & & & & & & -0.04 & 0.03 \\
\hline
\end{tabular}




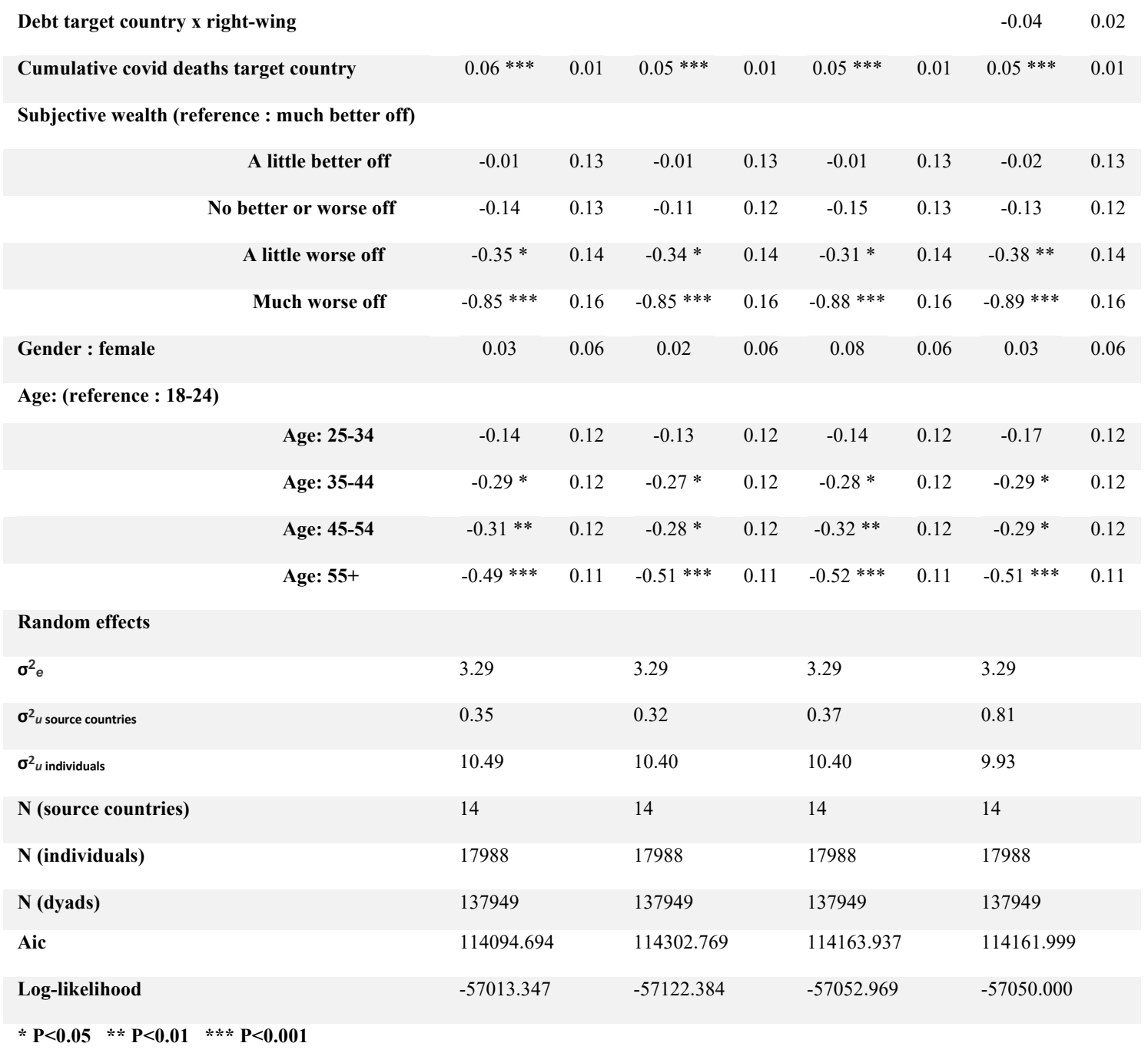

Next, we examine the moderating role of ideology for the use of need as a heuristic (model 9). We expected more left-wing individuals to be more likely to employ need as a heuristic for judging support for foreign countries (hypothesis 5c). Here, we actually find that right-wing individuals are more likely to use this heuristic at least regarding the importance of relative wealth. While left-wing individuals are more likely to support help unconditionally, once again we find that right-wing individuals display more conditional patterns of solidarity: left-wing individuals support help unconditionally, while right-wing individuals more readily support help for countries that are worse off than the one where they live. Somewhat paradoxically, the probability of support from right-wing individuals also increases as the GDP of the target country increases.

Finally, the model with attitude variables shows that ideology does not moderate the effect of debt on solidarity assessments. Generally, public debt isn't that a factor that seems to feature in individuals' assessment of solidarity with other countries, as the first set of models has shown. Things are different for corruption: the level of corruption of the target country has a different (more negative) impact on rightwing and centrist individuals compared to left-wing individuals. The impact of the level of democracy is not moderated by individual ideology: individuals across the ideological spectrum do not differ in the 
impact of the level of democracy potential recipient countries. Figure 2 plots the marginal effects for these interactions, showing one variable per heuristic and how it is moderated by ideology.

Figure 2: Predicted probabilities of support for financial help by characteristics of target country for individuals of different ideological dispositions
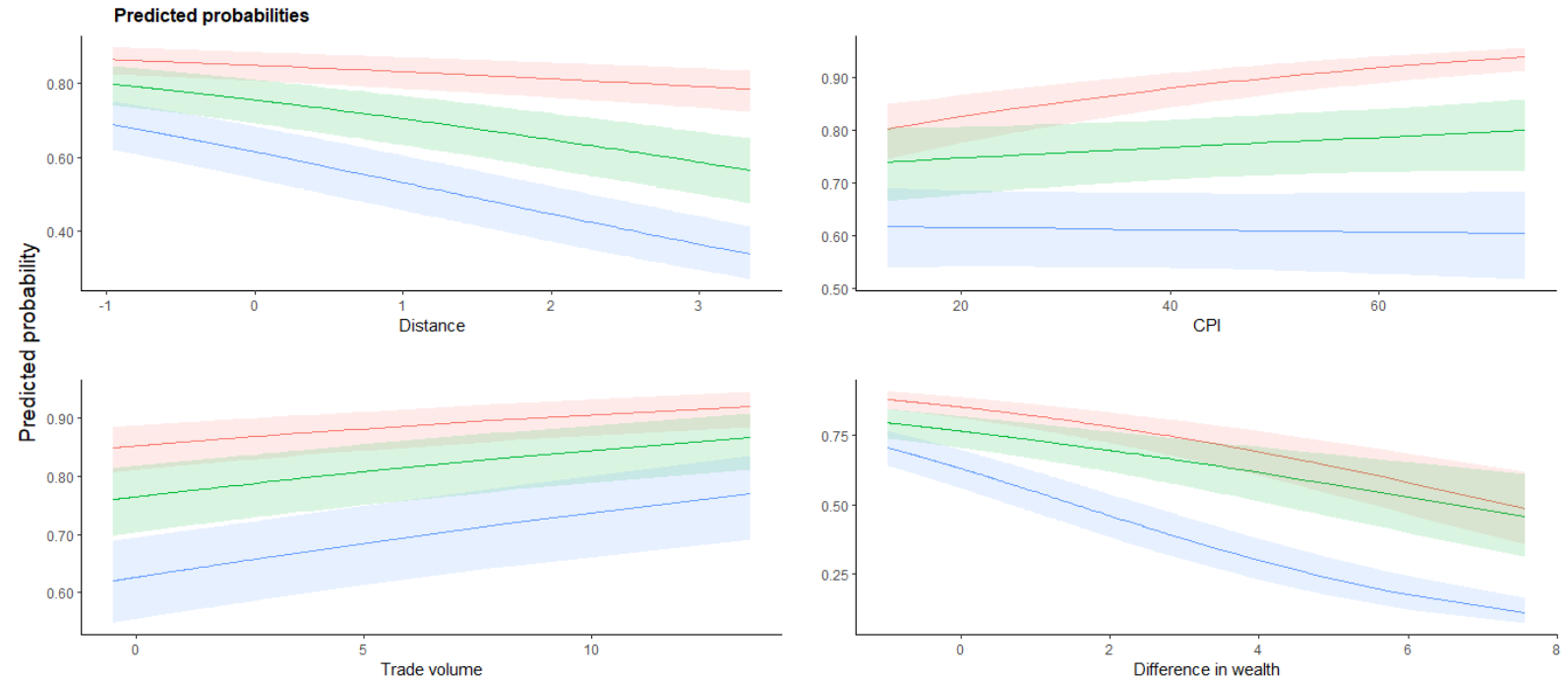

To make things more concrete, it may be useful to show how the likelihood of support for help across borders evolves across the ideological spectrum for specific countries. We do this in Figure 3, which shows predicted levels of support for help for Germany, Italy, Colombia and the United Kingdom across a sevenpoint scale of ideological positions, controlling for age, gender and country of respondent. We can see the clear pattern shown previously, namely a more conditional pattern of support as one moves to the right of the ideological spectrum: whereas very left-wing individuals do not differentiate between these countries in their propensity to support financial help, right-wing individuals display distinctly different levels of support for these countries, especially between European and non-European countries. 
Figure 3: Predicted probabilities of support for specific countries for individuals of different ideological dispositions

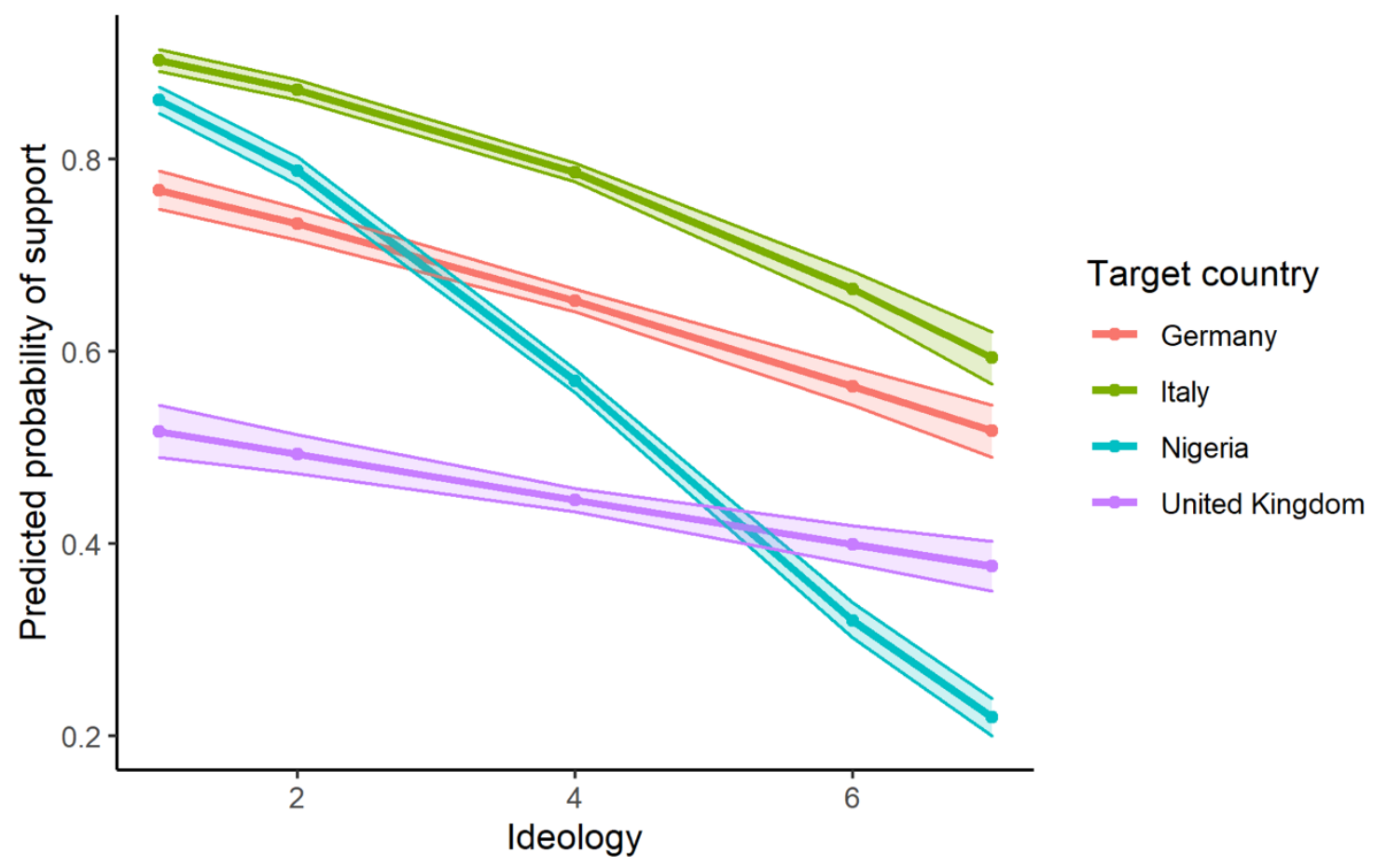

\section{Conclusion}

In this article, we have investigated how the characteristics of the target country influence the propensity of European individuals to support financial help for that country, and how these characteristics are moderated by ideology. We have shown that the heuristics of identity and need are especially important in guiding individual's assessments of whether their government should help a foreign country or not in the event of a crisis. In general, the support of right-wing individuals for helping foreign countries is much more conditional, especially on identity-related factors such as geographical proximity. Nevertheless, we have shown that despite the rise of Eurosceptic parties, there is a tangible sense of European solidarity in the sense that Europeans are much more likely to support financial help for fellow EU members than for nonmembers.

These results have a number of limitations and implications for policy. First, our results are based on a sample of European countries and the range of possible recipient countries, even if it is broader than the countries of respondents - is also relatively limited. Given the institutionalized system of cooperation and mutual responsibility already in place in the European Union, the extent to which these results would be similar in other areas of the world would need to be assessed. Similarly, the range of countries presented as possible recipients in the survey is also limited and a survey experiment providing a much wider range of potential recipients could offer a more granular assessment of how the different heuristics are deployed by individuals. While it would not be surprising that US citizens are more willing to support help for Canada 
than for Laos, there is a whole range of variation in the characteristics of target countries that would be need to be investigated further. Similarly, that actual empirical test of heuristics in our data was indirect, and it would be interesting to see the correspondence between beliefs in different values and how they relate to preferences for support for helping specific countries.

The policy implications of our findings are ambiguous. On the one hand, we are able to highlight the preferences of citizens in terms of the type of countries they are more likely to support financial assistance for. Now the extent to which public policy in the area of international redistribution should be guided by public preferences is debatable insofar as the level of information available to citizens on the specific needs of potential target countries is limited and, as we have shown, is likely to be driven by fairly superficial cues about geographic or cultural proximity. Rather than guiding foreign policy and financial assistance decisions, our research can potentially help policymakers understand resistance and support to international redistribution towards specific countries to craft messaging. The role of messaging and information is in this respect a promising avenue for research to investigate how the media and political elites shape support for helping some countries and not others.

\section{Bibliography}

Bailey, M., Cao, R., Kuchler, T., Stroebel, J., \& Wong, A. (2018). Social Connectedness: Measurement, Determinants, and Effects. Journal of Economic Perspectives, 32(3), 259-280. https://doi.org/10.1257/jep.32.3.259

Bansak, K., Hainmueller, J., \& Hangartner, D. (2016). How economic, humanitarian, and religious concerns shape European attitudes toward asylum seekers. Science, 354(6309), 217-222. https://doi.org/10.1126/science.aag2147

Bechtel, M. M., Hainmueller, J., \& Margalit, Y. (2014). Preferences for International Redistribution: The Divide over the Eurozone Bailouts. American Journal of Political Science, 58(4), 835-856. https://doi.org/10.1111/ajps.12079

Charness, G., \& Rabin, M. (2002). Understanding Social Preferences with Simple Tests. The Quarterly Journal of Economics, 117(3), 817-869. JSTOR. https://www.jstor.org/stable/4132490

Dimick, M., Rueda, D., \& Stegmueller, D. (2018). Models of Other-Regarding Preferences, Inequality, and Redistribution. Annual Review of Political Science, 21(1), 441-460. https://doi.org/10.1146/annurev-polisci-091515-030034

Elster, J. (2006). Altruistic behavior and altruistic motivations. Handbook of the Economics of Giving, Altruism and Reciprocity, 1, 183-206. 
Falk, A., Fehr, E., \& Fischbacher, U. (2008). Testing theories of fairness-Intentions matter. Games and Economic Behavior, 62(1), 287-303. https://doi.org/10.1016/j.geb.2007.06.001

Genschel, P., Hemerijck, A., Shakespeare, S., Van Parys, J., Cicchi, L., \& Nasr, M. (2020). EUI-YouGov survey on solidarity in Europe [Data set]. European University Institute, RSCAS. https://cadmus.eui.eu//handle/1814/67584

GeoDataSource. (n.d.). Country Borders Database. GeoDataSource. Retrieved 30 October 2020, from https://www.geodatasource.com/addon/country-borders

Gilens, M. (1999). Why Americans Hate Welfare: Race, Media, and the Politics of Antipoverty Policy (1 edition). University Of Chicago Press.

I\&O Research. (2020). Kiezers solidair met zuidelijke landen, maar niet tegen elke prijs-I\&O Research. https://www.ioresearch.nl/actueel/kiezers-solidair-met-zuidelijke-landen-maar-niet-tegen-elkeprijs/

Kleider, H., \& Stoeckel, F. (2019). The politics of international redistribution: Explaining public support for fiscal transfers in the EU. European Journal of Political Research, 58(1), 4-29. https://doi.org/10.1111/1475-6765.12268

Konow, J. (2003). Which Is the Fairest One of All? A Positive Analysis of Justice Theories. Journal of Economic Literature, 41(4), 1188-1239. https://doi.org/10.1257/002205103771800013

Kuhn, T., \& Kamm, A. (2019). The national boundaries of solidarity: A survey experiment on solidarity with unemployed people in the European Union. European Political Science Review, 11(2), 179195. https://doi.org/10.1017/S1755773919000067

Luttmer, E. F. P. (2001). Group Loyalty and the Taste for Redistribution. Journal of Political Economy, 109(3), 500-528. https://doi.org/10.1086/321019

Melitz, J., \& Toubal, F. (2014). Native language, spoken language, translation and trade. Journal of International Economics, 93(2), 351-363. https://doi.org/10.1016/j.jinteco.2014.04.004

Meuleman, B., Roosma, F., \& Abts, K. (2020). Welfare deservingness opinions from heuristic to measurable concept: The CARIN deservingness principles scale. Social Science Research, 85, 102352. https://doi.org/10.1016/j.ssresearch.2019.102352 
Molm, L. D., Collett, J. L., \& Schaefer, D. R. (2007). Building Solidarity through Generalized Exchange: A Theory of Reciprocity. American Journal of Sociology, 113(1), 205-242. https://doi.org/10.1086/517900

Petersen, M. B. (2012). Social Welfare as Small-Scale Help: Evolutionary Psychology and the Deservingness Heuristic. American Journal of Political Science, 56(1), 1-16. https://doi.org/10.1111/j.1540-5907.2011.00545.x

Picard, R. (2019). GEODIST: Stata module to compute geographical distances. In Statistical Software Components. Boston College Department of Economics. https://ideas.repec.org/c/boc/bocode/s457147.html

Scharpf, F. W. (2010). The asymmetry of European integration, or why the EU cannot be a 'social market economy'. Socio-Economic Review, 8, 211-250.

Shayo, M. (2009). A Model of Social Identity with an Application to Political Economy: Nation, Class, and Redistribution. American Political Science Review, 103(2), 147-174. https://doi.org/10.1017/S0003055409090194

Stjernø, S. (2005, February). Solidarity in Europe: The History of an Idea. Cambridge Core; Cambridge University Press. https://doi.org/10.1017/CBO9780511490378

Tajfel, H. (1974). Social identity and intergroup behaviour. Information (International Social Science Council), 13(2), 65-93.

The Growth Lab At Harvard University. (2019). International Trade Data (HS, 92) [Data set]. Harvard Dataverse. https://doi.org/10.7910/DVN/T4CHWJ

Transparency international. (2020). Corruptions Perceptions Index 2019. Transparency.Org. https://www.transparency.org/en/cpi/2019/index/nzl

van Oorschot, W. (2000). Who should get what, and why? On deservingness criteria and the conditionality of solidarity among the public. Policy and Politics, 28(1), 33-48.

Van Oorschot, W. (2006). Making the difference in social Europe: Deservingness perceptions among citizens of European welfare states. Journal of European Social Policy, 16, 23-42.

Walzer, M. (1983). Spheres of justice a defence of pluralism and equality. Blackwell.

Waytz, A., Iyer, R., Young, L., Haidt, J., \& Graham, J. (2019). Ideological differences in the expanse of the moral circle. Nature Communications, 10(1), 4389. https://doi.org/10.1038/s41467-019-12227-0 
World Bank. (2020). GDP per capita (current US\$)|Data.

https://data.worldbank.org/indicator/NY.GDP.PCAP.CD 